\title{
Ser uma pessoa, ser alguém. Os limites do institucionalismo hegeliano
}

\section{To be a person, to be someone. The limits of Hegelian institutionalism}

Catherine Colliot-Thélène

catherine.colliot@univ-rennes1.fr (Université de Rennes 1, Rennes, França)

Resumo: É geralmente aceito que a filosofia política de Hegel é institucionalista no sentido de que ela não se contenta em justificar a necessidade do organismo político, mas que ela expõe suas articulações complexas com esmero de precisão. Enquanto para alguns, como para Axel Honneth, por exemplo, 0 institucionalismo de Hegel seria excessivo, tenho, inversamente, a tendência de considerar que 0 interesse de Hegel pelo concreto das instituições é aquilo que constitui a força de sua filosofia política. Pareceme que encontramos nos Princípios da Filosofia do Direito os traços de uma reflexão (discreta) sobre os limites do institucionalizável. São esses traços que eu pretendo identificar, em dois níveis, nesta exposição: aquele do direito abstrato, que será objeto da primeira parte, e aquele da eticidade, ao qual consagrarei a segunda parte da exposição.

Palavras-chave: Hegel, Filosofia do Direito, institucionalismo, intersubjetividade.
Abstract: It's generally accepted that Hegel's political philosophy is institucionalist to the extent that he is not satisfied with justifying the necessity of a political body and exposes its complex articulations with care and precision. While some authors, like Axel Honneth, for example, consider his institucionalism excessive, I think, otherwise, that Hegel's interest for the concretude of institutions shows the force of his political philosophy. I argue that we can find in Principles of the Philosophy of Right, in two different levels, the traces of a discrete reflection on the limits of the institutionalizable: that of abstract right, object of the first section, and that of the ethical life, which occupies the second one.

Keywords: Hegel, Philosophy of Right, institutionalism, intersubjectivity. 
É geralmente aceito que a filosofia política de Hegel é institucionalista no sentido de que ela não se contenta em justificar a necessidade do organismo político e em estabelecer as normas abstratas cujo respeito condiciona sua legitimidade, mas que ela expõe as articulações complexas dessa organização com um esmero de precisão que a torna uma exceção no corpus de nossa tradição filosófica. ${ }^{1}$ Axel Honneth, que utilizou, como se sabe, o tema hegeliano do reconhecimento para dar uma nova forma e um novo impulso à teoria crítica, imputou ao Hegel dos Princípios da Filosofia do Direito um excesso de institucionalismo, o qual ele se aplicou em corrigir se apoiando principalmente nos textos mais antigos do filósofo. ${ }^{2}$ Tenho, inversamente, a tendência de considerar que o interesse de Hegel pelo concreto das instituições é aquilo que constitui a força de sua filosofia política, tanto em relação às teorias anteriores (as teorias do direito natural moderno, em geral, mas também Rousseau e Kant) quanto às teorias mais tardias, aí compreendidas até as do século XX. Parece-me, no entanto, que encontramos também, nos Princípios da Filosofia do Direito, os traços de uma reflexão (discreta) sobre os limites do institucionalizável. São esses traços que eu pretendo identificar, em dois níveis, nesta exposição: aquele do direito abstrato, que será objeto da primeira parte, e aquele da eticidade, ao qual consagrarei a segunda parte da exposição.

\section{Ser uma pessoa.}

O imperativo do direito abstrato e a crítica da escravidão.

Eu tomarei como ponto de partida o caráter desconcertante da formulação da prescrição do direito abstrato (§36): "seja uma pessoa e respeite os outros enquanto pessoas". ${ }^{3} \mathrm{O}$ que pode significar a in-

1. O termo "institucionalismo" congrega ainda muitas outras coisas, com as quais tem relação o normativismo e o decisionismo. Veja a este respeito KÉRVEGAN, J-F. L'effectif et Le rationnel. Paris: Vrin, 2007, e em particular sua distinção entre institucionalismo "forte" e institucionalismo "fraco" (Idem, p. $311 \mathrm{ss})$.

2. Cf. HONNETH, A. Les patbologies de la liberte; (Sofrimento de Indeterminação. Tradução de Rúrion Soares de Melo. São Paulo: Esfera Pública, 2007).

3. HEGEL, G. Grundlinien der Philosophie des Rechts. In: Werke in zwanzig Bänden, E. Moldenhauer e K. M. Michel (eds.). Frankfurt am Main: Suhrkamp, 1986, Werke 7, §36, p. 95. 
junção de ter de ser uma pessoa? Hegel anota, num dos parágrafos que se seguem (\$38), a propósito desse imperativo, que sua abstração se deve ao fato de que ele se limita ao aspecto negativo da liberdade, que ele consiste consequentemente em proibições. Essas proibições visam todos os atos que atentariam contra a personalidade, com tudo o que ela implica (principalmente e antes de tudo, a propriedade). A segunda parte do imperativo jurídico é facilmente compreensível nesta perspectiva: respeitar os outros enquanto pessoas é não infringir os direitos que são os seus enquanto tais. Mas como lidar com a primeira parte, que incide sobre a relação do indivíduo consigo mesmo? A personalidade jurídica (que é o que está em questão aqui) não é conferida a cada um pelo direito positivo do Estado racional?

A isso se acrescenta um segundo motivo de perplexidade, que concerne à posição de Hegel a respeito da escravidão, exposto na observação ao parágrafo 57 . Hegel sustenta aí a posição, à primeira vista chocante, de que a escravidão não pode ser condenada em absoluto. Seria preciso compreender que certos indivíduos ou certos povos não são maduros para a liberdade (como certos homens políticos frequentemente deixam escapar)? Lendo o texto de perto, parece que o que ele diz é algo sensivelmente diferente. Trata-se, para Hegel, de simplesmente apontar a insuficiência de uma crítica que se satisfaz em invocar a liberdade natural do homem para condenar a escravidão. Sem dúvida, a natureza é compreendida pelos críticos da escravidão de uma maneira diferente daqueles que, ao contrário, se referem a ela para justificar a escravidão. Esses últimos visam o ser natural dos homens tal como ele se dá a conhecer na facticidade. Invocam a história, que atesta a permanência da violência física, ou ainda a preocupação dos homens em simplesmente viver, que pode conduzi-los à submissão em troca de proteção. Todas estas determinações da existência humana têm frequentemente servido de argumento para legitimar a dominação. Ao contrário, aqueles que condenam a escravidão em absoluto não se referem aos fatos e à história, mas ao conceito de ser humano como espírito, o que implica em sua liberdade essencial. Hegel percebe aí uma antinomia que se deve à unilateralidade espelhada dos dois pontos de vista. Entretanto, as duas posições não são simétricas. Os críticos da escravidão, malgrado a unilateralidade de seu argumento, têm sobre seus adversários a vantagem de se situar no plano da razão, ou seja, de compreender o homem como uma vontade livre, enquanto seus adversários o reduzem a suas determinações naturais, aquelas que ele partilha com os animais. Os dois pontos de vistas são 
"imediatos", mas a imediatez não é a mesma conforme se a conceba a partir da existência natural ou antes a partir do conceito de espírito. Em que consiste, portanto, a insuficiência dos argumentos ordinários contra a escravidão? O final do parágrafo responde essa questão através de duas teses intercaladas. Ela remete, em primeiro lugar, à luta por reconhecimento e à relação entre dominação e servidão tal como são expostas na Fenomenologia do Espírito e na Enciclopédia. Essas duas célebres dialéticas - que constituem seguramente um todo e são geralmente tratadas como tal pelos comentadores, mas da qual é conveniente também distinguir os momentos (nós voltaremos a isso) - são o que permite, segundo Hegel, ultrapassar a representação do ser humano como ser natural, suscetível de ser escravo, e de elevar-se assim ao "ponto de vista da vontade livre, com o qual principia o direito e a ciência do direito". ${ }^{4}$ Mas isto não é senão um começo. Para que esta determinação do humano à liberdade não permaneça um simples postulado (um Sollen) - deve-se, além disso, reconhecer - eis o segundo argumento - "que a Ideia da liberdade só é verdadeiramente como Estado". ${ }^{5}$ Em outras palavras: a organização política, condição da existência do direito objetivo, é necessária para se passar da simples postulação subjetiva da liberdade à sua realidade.

Hegel já havia feito uma referência, em um parágrafo anterior da Filosofia do Direito, às passagens da Fenomenologia de 1807 e da Enciclopédia que precedem diretamente a luta das consciências. Este parágrafo (\$35) explica o que significa a noção de "pessoa". A pessoa é um indivíduo singular (um "este"), determinado, ao mesmo tempo, por suas propriedades exteriores (constituição e aparência física) e pela particularidade de seus desejos, impulsos e vontades, ${ }_{i}$ mas também um indivíduo que se compreende a si mesmo como transcendendo todas essas particularidades que faz dele um ser finito, um indivíduo que afirma sua identidade a si próprio na medida mesma em que ele é capaz de se retirar dessas determinações particulares. Um indivíduo é uma pessoa não em virtude de sua singularidade, mas, ao contrário, porque ele pode se afastar dela. A liberdade reside na possibilidade deste afastamento. Hegel remete, aqui, às passagens da Fenomenologia e da Enciclopédia que expõem aquilo que é a consciência de si "segundo

4. Idem, §57, pp. 123-124.

5. Idem, §57, p. 124. 
a vontade natural e as oposições ainda exteriores dela"6 e, assim, implicitamente, ao que se segue a essas passagens, a luta das consciências e a dialética do senhor e do escravo, para precisar a oposição entre o sujeito consciente de si como indivíduo singular e este mesmo sujeito consciente de si como pessoa. Ele indica, assim, que a luta das consciências e a dialética do senhor e do escravo constituem a gênese fenomenológica da pessoa, anterior à sua fixação jurídica.

Essa anterioridade é revelada em um outro parágrafo da Filosofia do Direito, que menciona ainda, de maneira mais alusiva, a luta das consciências e a confrontação entre o senhor e o escravo, e ela é aqui claramente concebida como uma anterioridade histórica. "Antes do começo da história efetiva", anota Hegel numa observação ao parágrafo 349, cumpre dizer, antes da existência de uma organização política que pudéssemos considerar como Estado, não havia senão "inocência apática, desprovida de interesse" e, de outro lado, "a bravura do combate formal pelo reconhecimento e a da vingança". ${ }^{7} \mathrm{~A}$ Enciclopédia (edição 1827/1830, adendo ao \$432) é mais explícita quanto à significação pré-histórica da luta por reconhecimento. Hegel assinala aí, com efeito, que esta luta "na forma extremada em que ela é apresentada aqui [in der angegebenen bis zum Äußersten getriebenen Form]"s não pode se encontrar a não ser no estado de natureza e que ela é, ao contrário, exterior à sociedade civil e ao Estado, pois o resultado dessa luta, a saber, o reconhecimento, já está dado nas relações desenvolvidas que são as das sociedades éticas. O reconhecimento recíproco dos homens como consciências de si é posto e pressuposto pelo Estado. Ou melhor, convém precisá-lo, pelo Estado racional. Pois há uma pré-história do Estado que dá larga margem à violência, bem como às relações de dominação. A violência não é o fundamento do Estado, mas ela está muitas vezes em sua origem: "Pois, embora possa nascer mediante a violência, o Estado não repousa sobre ela: a violência somente trouxe à existência algo legítimo em si: as leis e a constituição. O que domina no Estado são o espírito do povo, os costumes,

6. Idem, $\$ 35$, p. 94 .

7. Idem, 3349, p. 507.

8. HEGEL, G. Enzyklopädie der philosophischen Wissenschaften im Grundisse. Dritter Teil. In: Werke in zwanzig Bänden, Werke 10, p. 221; (Enciclopédia das Ciências Filosóficas III. São Paulo: Loyola, 1995. p. 203). 
a lei" ${ }^{9}$ Hegel enfim retorna a este tema na observação ao parágrafo 433 da Enciclopédia: ele trata, ali, não mais do momento inicial da luta das consciências, mas do que a segue, a relação dominação/servidão e da violência nela implicada. A submissão a um senhor é um fenômeno que encontramos nos começos dos Estados e a violência que ela encerra, ele nos diz uma vez mais, não é fundamento do direito, ainda que seja um momento necessário e legítimo na passagem da consciência de si mergulhada no desejo e na singularidade para a consciência de si universal. "É o começo necessário ou fenomênico dos Estados, não seu princípio substancial". ${ }^{10}$

Malgrado as passagens citadas, as referências às passagens célebres da Fenomenologia de 1807 é marginal na Filosofia do Direito e é natural que muitos dos comentadores dessa obra não tenham se detido aí. Para a compreensão das diferentes esferas do direito - o direito abstrato, a moralidade e a eticidade em seus diferentes níveis (família, sociedade civil e Estado) - ou ainda para aquela da organização das instituições do Estado proposta por Hegel, a luta das consciências e a relação de senhor e escravo, relegadas à pré-história, parecem sem importância. E somos tentados a censurar Kojève por ter implementado uma interpretação política da filosofia hegeliana focalizando um texto que não pertencia à parte propriamente política dessa filosofia. Sem aderir ao conjunto da interpretação de Kojève, creio que nós devemos, contudo, concordar com ele que a "pré-historicidade" da luta das consciências e da dominação do senhor sobre o escravo sob as formas "mais extremas" não implica que nós tenhamos terminado com elas nas condições dos Estados desenvolvidos. Eu o seguirei, portanto, e com ele Hyppolite, que contestava que a luta por reconhecimento fosse um momento particular da história ou da pré-história humana, "da qual se poderia fixar a data", e via aí, ao contrário, "uma categoria da vida histórica, uma condição da experiência humana que Hegel descobre pelo estudo das condições de desenvolvimento da consciência de si"."1

9. Idem, ibidem; (Idem, ibidem).

10. Idem, p. 223; (Idem, p. 204).

11. HYPPOLITE, J. Genèse et structure de la Phénoménologie de l'Esprit de Hegel. Paris: Aubier, 1946, p. 164(Gênese e estrutura da Fenomenologia do Espírito de Hegel. São Paulo: Discurso Editorial, 1999, p. 185.) 
Para compreender a significação transistórica e, por consequência, antropológica dessas duas dialéticas, devemos retornar ao nosso ponto de partida, ou seja, ao caráter enigmático da injunção: "seja uma pessoa". O enigma se deve a que, ali onde essa injunção é formulada $(F D, \S 36)$, a pessoa ou a personalidade se confunde com a capacidade jurídica, a qual é conferida a cada um pelo direito positivo do Estado, em sua parte abstrata, que é também (malgrado sua insuficiência) a mais fundamental. Conferida e, por consequência, reconhecida, sem que o indivíduo tenha que se engajar numa luta qualquer para obter esse reconhecimento. É nesse sentido, bem compreendido, que a luta das consciências pelo reconhecimento mútuo de sua liberdade pode ser considerada como arcaica e repelida para o "antes" da história efetiva. A institucionalização da liberdade pelo direito formal do Estado racional parece desincumbir o indivíduo da obrigação de provar que ele é um ser livre, nos termos de Hegel: que ele é consciência de si em si e para si. Nos tempos antigos anteriores ao Estado, a liberdade podia ser negada a um indivíduo ou a um povo que não estivesse pronto a lutar por sua conquista ou conservação. Assim pode Hegel afirmar que (FD, §57 obs., e Enc. §435, adendo)

aos que [entre os povos] permanecem escravos, não se faz nenhuma injustiça absoluta, pois quem não possui a coragem de arriscar a vida pela conquista da liberdade, esse merece ser escravo; e se, ao contrário, um povo não somente imagina que quer ser livre, mas tem efetivamente a vontade enérgica da liberdade, nenhum poder humano poderá retê-lo na servidão e o fazer suportar ser governado. ${ }^{12}$

A servidão é, de uma certa maneira, sempre voluntária como diz explicitamente a continuação deste adendo: "...que alguém seja escravo se deve à sua própria vontade, assim como se deve à vontade de um povo que ele seja subjugado. Não é, pois, simplesmente uma injustiça daqueles que fazem escravos ou que assujeitam, mas uma injustiça dos próprios escravos e sujeitados". ${ }^{13}$ Mas as instituições do Estado racional colocam precisamente um termo a estas condições nas quais uma injustiça (um não-direito) pode ser ainda de direito, ou seja, afiançada pelo direito positivo. No quadro dessas instituições, os indivíduos não devem mais conquistar a liberdade, ela lhes é dada. Que

12. HEGEL, G. Enzyklopädie, p. 225 (Enciclopédia, p. 206).

13. HEGEL, G. Grundlinien der Pbilosopbie des Rechts, §57 Zusatz, p. 126. 
pode significar nestas condições, uma vez mais, a injunção: "seja uma pessoa"?

Aproximamo-nos da solução desse enigma voltando ao corpo do parágrafo, cuja glosa constitui a observação sobre a escravidão que comentamos até o momento. Este parágrafo trata da formação (Ausbildung) necessária a cada um de seu corpo e de seu espírito, formação por meio da qual o indivíduo toma posse de si e se torna propriedade de si mesmo em relação aos outros. Sem dúvida, a teoria hegeliana do direito abstrato é uma teorização e justificação da propriedade privada, e leitores de inspiração marxista (e mesmo Marx) não deixaram de criticá-lo, mas esqueceram na maior parte do tempo que a justificação da propriedade incluía a propriedade de si mesmo e que, longe de ser um aspecto marginal, esta propriedade muito particular é, sem dúvida, ao contrário, a razão fundamental pela qual a propriedade privada das coisas pode ser considerada como uma manifestação da liberdade. Como observou Etienne Balibar a respeito de Locke, ${ }^{14}$ os teóricos modernos do direito natural sempre associaram a crítica da escravidão e a justificação da propriedade privada. $\mathrm{O}$ escravo não pode ser proprietário, no sentido forte do termo, porque ele é propriedade de um outro. Reconhecer para um indivíduo o direito de ser proprietário é retirá-lo da condição de escravo ou de servidão. Todavia, o indivíduo, assim entregue a si mesmo, deve tomar posse de si mesmo tal como ele deve se apropriar das coisas. A liberdade, entendida como independência em relação ao arbítrio de outro, não é senão o começo (uma simples possibilidade, diz Hegel) de um processo de formação cuja responsabilidade incumbe inteiramente ao indivíduo livre.

O medo da morte e o trabalho.

Não devemos, portanto, nos espantar de encontrar associados, nesse parágrafo e na sua observação, os dois aspectos da formação da e para a liberdade que já estavam presentes nas duas dialéticas da "consciência de si" da Fenomenologia: a exposição ao risco de morte, de uma parte, e o trabalho, de outra. A significação fundamental do risco de morte é apenas indicada indiretamente através da referência à

14. BALIBAR, E. Identité et différence: An Essay concerning Human Understanding II, xxcii, Of Identity and Diversity: L'invention de la conscience. Apresentação, tradução e comentários por E. Balibar. Les Éditions du Seuil, 1998. 
Fenomenologia, e o trabalho não é designado como tal, mas é subentendido nessa formação do corpo e do espírito, pela qual o indivíduo toma posse de si mesmo. Mas o essencial daquilo que é desenvolvido longamente nas passagens em questão na Fenomenologia se encontra nesta passagem da Filosofia do Direito, a saber, que a liberdade real é um processo, uma Bildung, por meio do qual o homem se forma, ao mesmo tempo em que transforma a natureza exterior. A luta de morte pelo reconhecimento é a condição inaugural (ideal), pois o trabalho não pode ter a significação de uma Bildung (apropriação do mundo exterior que é ao mesmo tempo formação de si) a não ser na condição de não aparecer unicamente para o indivíduo trabalhador como uma necessidade puramente material, imposta pela indigência ou pela vontade de outrem. A inversão que conhece a significação do trabalho na descrição fenomenológica da relação dominação/servidão é essencial à compreensão da dinâmica dessa relação. Não é, com efeito, do lado do senhor que o futuro da cultura se decide, mas do lado da consciência servil, e isso, precisamente porque o trabalho, que aparece em primeiro lugar como uma coação, se prova como o meio de afirmação de uma liberdade infinitamente superior àquela do senhor. Somente a consciência servil consegue reunir os dois momentos necessários de acesso à liberdade real: a confrontação com o risco de morte e a transformação do mundo objetivo natural pelo trabalho humano. É o poder de interpretar o trabalho, ao qual ele é coagido à luz da experiência possível de morte, é o que permite ao servo revolver o sentido dele. Hegel o indica através de um jogo de palavras que opõem o sentido próprio (Eigner Sinn) e obstinação (Eigensinn). ${ }^{15}$

Chega um momento em que a consciência servil, coagida ao trabalho pela vontade do senhor, descobre que, precisamente pelo trabalho, ela se apropria da objetividade. O objeto não é mais a coisa alheia, mas, porque o servo lhe dá forma através do trabalho, ela se torna sua própria expressão: a forma, ainda que imposta a uma coisa exterior, não recai na exterioridade, mas "precisamente no trabalho, em que parecia ser apenas um sentido alheio, vem a ser sentido próprio". ${ }^{16}$ Todavia, se a consciência não havia feito anteriormente a prova do

15. Cf. HEGEL, G. Phänomenologie des Geistes. In: Werke in zwanzig Bänden, Werke 3. p. 154. (Fenomenologia do Espírito. Petrópolis: Vozes, 2012, $\S 196$, p. 151).

16. Idem, ibidem, (Idem, ibidem). 
temor absoluto, se ela não havia estremecido até o fundo de si mesma antecipando não a perda de uma parte contingente de seu ser, mas a desaparição de seu ser mesmo, a atividade formativa (pois, no fundo é bem possível que os homens trabalhem sem passar pelo terror de morrer e ter de consentir à servidão para escapar da morte) seria "sentido próprio apenas presunçosamente": "o sentido próprio é obstinação, uma liberdade que ainda permanece no interior da escravidão". ${ }^{17}$ Aquilo que Hegel quer dizer é que não é a capacidade que o homem tem em geral de transformar, através de sua atividade, as coisas da natureza que lhe permite reconhecer nesta coisidade transformada a expressão de seu ser próprio. Reconhecer e reivindicar o produto de seu trabalho como sua obra pode ser tão-somente uma simples manifestação de vaidade, que se conjuga sem dificuldade com a convicção mantida de que a natureza em geral é algo de autônomo em relação à consciência individual. $\mathrm{O}$ trabalho não tem a significação especulativa que lhe confere Hegel nessa passagem a não ser na medida em que ele é apreendido como atividade formativa através da qual a consciência se dá a única objetividade durável possível, aquela de um mundo transformado por ela. Ou, para que a consciência confira essa significação ao trabalho, é preciso que esteja em causa o sentido de sua vida. Por esta razão, parece-me que as interpretações existenciais da luta das consciências, tal como ela está exposta nas duas dialéticas da Fenomenologia, merecem ser tomadas em consideração. O que mantém juntos os dois momentos distintos que são a luta das consciências e a relação dominação/servidão, o que dá seu sentido unitário à sua justaposição, é o fato de que o trabalho pode ser reinterpretado e seu sentido invertido à luz da consciência da finitude. Somente um ser que se sabe mortal pode conceber seu trabalho e o produto de seu trabalho como expressão de sua autonomia.

Ao cabo dessas duas dialéticas, é finalmente o servo quem triunfa. Das duas inversões que Hegel menciona em paralelo, aquela do reconhecimento conferida ao senhor e aquela da negação do reconhecimento que é a base da servidão, só a segunda labora no sentido de uma superação do antagonismo. O senhor recebe o reconhecimento

17. Idem, pp. 154-155; (Idem, ibidem). No original: "Formiert das Bewußtsein ohne die erste absolute Furcht, so ist es nur eine itler eigner Sinn [...] der eigne Sinn ist Eigensinn, eine Freiheit, welche noch innherhalb der Knechtschaft stehen bleibt". 
procurado por parte da consciência servil, o qual não pode satisfazê-lo; a consciência servil, em contrapartida, "ao se realizar cabalmente", torna-se "o contrário do que é imediatamente; como consciência recalcada, ela voltará a si mesma e se converterá em verdadeira independência". ${ }^{18}$ Mas é preciso compreender que essa vitória final não é possível a não ser por essa inversão do sentido do trabalho à luz da experiência da finitude. É preciso que essa consciência tenha tido temor "não por isso ou aquilo, não por este ou aquele instante, mas sim por seu ser inteiro", ${ }^{19}$ que ela tenha "experimentado o medo da morte, do senhor absoluto". ${ }^{20} \mathrm{O}$ temor do senhor não é senão o "início da sabedoria", ${ }^{21}$ mas sem o medo do senhor absoluto o trabalho não poderia ter a significação antropológica que lhe confere Hegel.

Se o tema do trabalho, ou aquele mais geral da Bildung, é apresentado como um fio vermelho ao longo de toda a Filosofia do Direito, aquele da consciência da mortalidade o é bem menos. Devemos crer que a institucionalização do reconhecimento da liberdade na linha da capacidade jurídica conferida a cada um desincumbe o indivíduo da obrigação de provar que ele é uma pessoa, o que explicaria o confinamento da luta de morte entre as consciências à pré-história? Um certo número de textos convergem nessa direção, deixando entender que, quando o Estado atingiu um certo nível de desenvolvimento, os indivíduos encontram sua liberdade no respeito a suas leis. A luta por reconhecimento teria se tornado inútil, tanto para o indivíduo quanto em suas formas coletivas. As guerras sangrentas dos escravos na Roma antiga visavam o reconhecimento de seus direitos universais, e elas eram nesse sentido legítimas, mas somente porque os povos antigos, gregos e romanos, haviam feito da liberdade o privilégio de poucos. ${ }^{22}$ O esquema da luta por reconhecimento pode justificar, do ponto de vista histórico, a violência daqueles aos quais esse reconhecimento é negado. ${ }^{23}$ Desde o momento em que a personalidade é reconhecida

18. Idem, p. 152; (Idem, §193, p. 149).

19. Idem, p. 153; (Idem,\$194, p. 149).

20. Idem, ibidem (Idem, ibidem).

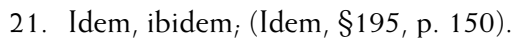

22. HEGEL, G. Enzyklopädie, p. 224; (Enciclopédia, §433, Adendo, p. 205.)

23. Cf. ainda $F D \S 57$ addendum, em que Hegel faz alusão à revoltas dos negros nas Índias Ocidentais. Essas revoltas fracassam porque seus autores "são vítimas da situação em geral". Mas, acrescenta Hegel de forma bastante elíp- 
em todos, essa justificação cai. Outros textos sugerem, contudo, que a liberdade não tem realidade a não ser através da ação do indivíduo, o que implica, por um lado, que o indivíduo deve perseguir sem descanso o trabalho da Bildung, trabalho indissociável sobre o mundo exterior e sobre si mesmo, sem a qual a liberdade permaneceria aquela do senhor, vaidosa e estéril, mas que ele deve ser sempre capaz de colocar sua vida em jogo para conservar a seu trabalho a significação antropogênica. Uma passagem da Fenomenologia diz explicitamente que o reconhecimento de um indivíduo como pessoa pelo direito objetivo pode permanecer formal, privada de significação do ponto de vista do espírito: "o indivíduo que não pôs sua vida em jogo pode, certamente, ser reconhecido como pessoa, mas não alcançou a verdade desse reconhecimento como sendo aquela de uma consciência de si autônoma". ${ }^{24}$ Se as instituições do Estado moderno conferem personalidade jurídica aos indivíduos, este reconhecimento puramente institucional não impede que o indivíduo enquanto tal (este indivíduo determinado) tenha experimentado efetivamente a prova de sua autonomia, cumpre dizer, de sua capacidade de ser livre. As instituições políticas não são, portanto, suficientes para assegurar a existência da liberdade. Elas são, seguramente, necessárias, mas não podem subsistir senão na medida em que os indivíduos que elas organizam efetuam sobre si mesmos e individualmente o trabalho da Bildung, mas também na medida em que eles estão sempre prontos para sacrificar sua vida, caso isso se mostre necessário, para se subtrair da servidão. Kojève tocava num ponto preciso quando escrevia que "esse trabalho servil só tem uma virtude antropogênica na medida em que nasce da angústia da morte e é acompanhado pela consciência da finitude essencial daquele que serve pelo trabalho ${ }^{\prime \prime 25} \mathrm{e}$, acentuando o argumento, que

o objeto final do devir humano é, segundo Hegel, a síntese da existência guerreira do senhor e da vida laboriosa do escravo. O homem que está plenamente satisfeito com sua existência e que

tica, "Eles podem, contudo, morrer como livres". (HEGEL, G. Vorlesungen über Rechtsphilosopbie 1818-1831, Band 2. Karl-Heinz Ilting. Frommann-Holboog (Eds.).Stutttgart: Bad-Constatt, 1974, p. 337).

24. HEGEL, G. Pbänomenologie, p. 149; (Fenomenologia,\$187, p. 146).

25. KOJÈVE, A. Introduction à la lecture de Hegel. Paris: Gallimard, 1968, p. 571-572; (Introdução à leitura de Hegel. Rio de Janeiro: Contraponto, Ed. UERJ, 2002, p. 533). 
conclui assim a evolução histórica da humanidade é o cidadão do Estado universal e homogêneo, isto é, segundo Hegel, o trabalhador-soldado dos exércitos revolucionários. ${ }^{26}$

$\mathrm{Na}$ Filosofia do Direito, o tema da luta pela liberdade esmaece em comparação com os textos anteriores. $\mathrm{O}$ que o indivíduo deve ter feito para merecer ser reconhecido como pessoa parece se reduzir à obediência às leis, o que é dito claramente na Enciclopédia:

No Estado, o homem é reconhecido e tratado como ser racional, como livre, como pessoa ${ }_{i}$ e de seu lado o indivíduo se torna digno desse reconhecimento porque, com a superação da naturalidade de sua consciência de si, obedece a um universal, à vontade que é em si e para si, à lei, portanto, comporta-se para com os outros de uma maneira universalmente válida, reconhece-os como aquilo pelo que ele mesmo quer valer: como livre, como pessoa. ${ }^{27}$

A Filosofia do Direito descreve as condições de um Estado bem constituído no qual a virtude dos cidadãos se manifesta na vida cotidiana, na retidã $\mathrm{O}^{28}$ (Recbtschaffenheit), o respeito aos deveres gerais e a realização dos deveres atribuídos a cada um em função do lugar que ocupam na totalidade da organização sócio-política. A necessidade de exposição ao risco de morte, contudo, não desaparece, ela é simplesmente transferida para o dever de o cidadão estar pronto a sacrificar sua propriedade e sua vida quando a independência e a soberania no Estado que lhe asseguram as condições de sua liberdade estão em perigo. É isso o que Hegel denomina "o momento ético da guerra": ${ }^{29}$ a luta por reconhecimento deslocada do plano individual, apresentado na Fenomenologia, para o plano das obrigações do indivíduo. Admitindo hipoteticamente que os ordenamentos institucionais que ele descreve são aqueles de um Estado racional, Hegel excluí a possibilidade de que os indivíduos tenham necessidade de retomar a luta sob sua forma a mais elementar, "exacerbada", pondo em risco de suas próprias vidas, eventualmente contra as autoridades oficiais de seu Estado. Se Hegel concedeu demasiado à instituição, foi precisamente

26. Idem, p. 562; (Idem, p. 525).

27. HEGEL, G. Enzyklopädie, pp. 221-222; (Enciclopédia, §432, Adendo, p. 203).

28. HEGEL, G. Grundlinien der Pbilosopbie des Recbts, §150, p. 298.

29. Idem, §324, p. 492. 
nesse ponto. Instruídos pela história do século $\mathrm{XX}$ europeu, e aquela do começo do século XXI, nós podemos, hoje, lhe objetar que a virtude excepcional, e mesmo o heroísmo, podem ser ainda requeridos sob as condições modernas, não somente porque vários Estados estão longe de ter conquistado a forma que ele dizia ser aquela de um Estado racional, mas também porque as instituições de Estado algum estão protegidas, seja o que for que ele tenha pensado a respeito disso, de uma eventual degeneração. A exigência fundamental sobre a qual repousa a possibilidade da liberdade é sempre reatualizável, e se segue dessa exigência de que a Filosofia do Direito não possa ser interpretada como uma apologia do positivismo jurídico. Submeter-se às leis de um Estado repressivo não pode ser considerado um modo de afirmar-se como pessoa. Na medida em que a noção de pessoa inclui aquela de liberdade, e mesmo se confunde com ela, a injunção: "seja uma pessoa" implica sempre simultânea e indissociavelmente o dever de se formar pelo trabalho e pela cultura, e de querer a liberdade aceitando, se for o caso, colocar a sua vida em jogo para conservar a sua liberdade.

\section{Ser alguém.}

Ser uma pessoa, nada mais que uma pessoa?

O significado da noção de pessoa ultrapassa, por consequência, seu sentido estritamente jurídico. Ainda que muito pouco indicada na Filosofia do Direito, a gênese fenomenológica da pessoa permanece indispensável à compreensão especulativa do que é o direito, a não ser que se queira reduzir este à sua dimensão objetiva. Mas, se admitimos que tantas coisas estão implicadas na noção de pessoa (a vontade de liberdade, eventualmente o risco de morte, e o duro trabalho de formação de si mesmo e do mundo exterior), defrontamos com uma nova dificuldade. Em certas passagens, com efeito, Hegel parece fazer pouco caso da qualificação do indivíduo como pessoa: assim se afigura o capítulo da Fenomenologia consagrado à condição jurídica ("o estado de direito" $\left.{ }^{130}\right)$, o qual podemos ler como uma interpretação da situação do Império Romano, mas que é também, de forma mais geral, uma análise do conceito de direito, entendido no sentido restrito do direito "abstrato" da Filosofia do Direito. Ali, Hegel estabelece um para-

30. HEGEL, G. Phänomenologie, Cap. VI, Parte A, Subseção c: "Der Rechtszustand", p. $355 \mathrm{ss}_{i}$ (Fenomenologia, pp. 331 ss.) 
lelo entre este conceito de direito e as disposições existenciais das quais o estoicismo e o ceticismo antigos foram a expressão teórica. Em um e no outro caso, o que é valorizado é a liberdade abstrata dos indivíduos e, com ela, a igualdade de todos enquanto indivíduos indiferenciados. A substância dos indivíduos é reduzida aqui à universalidade abstrata, o "si seco", ${ }^{31}$ como diz Hegel. Cada qual é reconhecido como livre, mas seu ser não é nada mais que esta identidade vazia de um "Um" qualquer, não distinguível de um outro. Podemos seguramente, sobre essa base, justificar a propriedade privada, mas esta se encontra sem nenhuma relação essencial com a particularidade do proprietário, o qual pode tomar posse de um objeto, aliená-lo, tomá-lo de um outro, mas sem se engajar de nenhuma maneira: o "meu" permanece uma forma vazia. Esses poucos parágrafos, que constituem uma crítica devastadora do formalismo jurídico, terminam na observação de que a consciência jurídica testemunha uma perda de realidade e de uma total inessencialidade, de tal sorte que "qualificar um indivíduo como pessoa é expressão de desprezo". ${ }^{32}$ Devemos crer que a posição de Hegel a respeito do direito abstrato se alterou no decurso dos anos que separam a redação da Fenomenologia (1807) da redação da Filosofia do Direito (1821)? Tal alteração parece pouco verossímil, na medida em que a crítica ao formalismo jurídico é retomada, grosso modo, nos mesmos termos nos comentários consignados nos addenda, comentários que Hegel adicionou na ocasião de seus cursos aos parágrafos iniciais do "direito abstrato" da Filosofia do Direito. Na ocasião mesma em que Hegel explica a significação da personalidade, ligando-a à capacidade do indivíduo de se elevar acima das determinações "imediatas" (§35), e bem antes de enunciar o imperativo jurídico ("seja uma pessoa e respeite os outros como pessoas", §36), Hegel observa que "o que há de mais elevado no homem é ser pessoa, mas, apesar disso, a mera abstração pessoa é, já na sua expressão, algo desprezível" ${ }^{33}$ A pessoa, complementa ainda, "é simultaneamente a grandeza e a pequenez extrema". ${ }^{34}$

31. Idem, p. 355; (Idem, §478, p. 332).

32. Idem, p. 357: "UndeinIndividuumalseine Person bezeichnenist der Ausdruck der Verachtung"; $($ Idem, $\$ 480$, p. 334).

33. HEGEL. Grundlinien der Pbilosopbie des Rechts, §35 Zusatz, p. 95.

34. Idem, ibidem. 
Dir-se-á que a posteridade não ignorou esta crítica ao formalismo jurídico na filosofia política hegeliana, e que certas leituras de Hegel que foram por bom tempo muito influentes tiveram mesmo a tendência de sublinhá-la, fazendo dessa crítica um dos pontos nodais da oposição entre o liberalismo kantiano e o estatismo hegeliano. Hegel, dizem, teria tomado o contrário da tese kantiana, segundo a qual a política deve dobrar os joelhos diante do direito, ${ }^{35}$ ao subordinar o direito à força do Estado. Eu não vou me deter nessa leitura, precisamente corrigida notadamente por Jean-François Kervégan, o qual nos convida a distinguir dois sentidos de antijuridismo: a hostilidade ao direito e a hostilidade ao juridismo, ou seja, à absolutização do direito. É somente no segundo sentido do termo que se pode falar de um antijuridismo de Hegel. Minha questão não se refere, contudo, senão de uma maneira indireta, a essas relações que Hegel estabeleceu entre o direito e o Estado, mas à aparente ambivalência de seu juízo acerca da noção de pessoa. Se nós concedemos que essa noção congrega toda a riqueza de significações que indicamos acima, se ela não se restringe à capacidade jurídica concedida pelas instituições do Estado racional, como pode ser possível que qualificar alguém de pessoa possa ser considerado uma expressão de desprezo? Ou devemos admitir que há duas acepções diferentes de pessoa? Essa hipótese, parece-me, deve ser rejeitada, pois, como mostramos, há uma continuidade entre a acepção fenomenológica e a acepção jurídica de pessoa. Reside já na primeira acepção a imperfeição que pode servir a um uso depreciativo da expressão. Vimos que um indivíduo pode ser juridicamente reconhecido como pessoa sem ter chegado à verdade disso que esse reconhecimento implica, cumpre dizer, sem tê-lo merecido. Não é, contudo, este intervalo possível entre o estatuto jurídico do indivíduo e seu merecimento que é visado no uso pejorativo do termo pessoa, mas o fato de que ele não seja nada além de uma pessoa, noutros termos: que ele não seja alguém. Na seção da Fenomenologia sobre o estado de direito, Hegel sublinha fortemente, através dos paralelos com o estoicismo e ceticismo antigos, que a insistência em "ser uma pessoa" se acompanhava de uma fuga diante da realidade da existência concreta. Os conteúdos particulares que dão consistência singular à vida de um indivíduo determinado são, assim, abandonados à contingência. $\mathrm{O}$

35. KANT, I. Zum ewigen Frieden. Berlin: Akademie Verlag, 1995, final do apêndice 1 ; (A paz perpétua e outros opúsculos. Portugal: Edições 70, 2008). 
estatuto social (que deve ser distinguido do estatuto jurídico), a atividade profissional, as relações familiares, associativas, políticas, etc., em suma, toda a realidade múltipla e complexa das relações sociais nas quais cada um está comprometido de maneiras diferentes, aparecem inessenciais, indiferentes ao ser do indivíduo. Ora, esse vazio de determinações particulares significa, precisamente, a abstração do direito abstrato. O direito abstrato não tece relações sociais, ele somente lhes abre a possibilidade, sobre a base da liberdade, ou seja, a ausência de dominação.

Deve-se reconhecer a extensão dessa insuficiência fundamental do direito abstrato do ponto de vista da vida social real para perceber que o reconhecimento da pessoa, tanto em sua acepção fenomenológica quanto na tradução jurídica desta, não esgota o problema do reconhecimento, problema que a leitura de Honneth realçou. A bem da verdade, se é essencial às instituições da liberdade que o indivíduo seja reconhecido como personalidade abstrata, o é igualmente que ele seja reconhecido como "alguém": um indivíduo singular, particularizado pelo lugar que ele ocupa e as atividades que são as suas na trama organizada da sociabilidade concreta. A extensão inabitual com que Hegel emprega a noção de direito e que lhe permite incluir sob o título de "filosofia do direito" os desenvolvimentos que abrangem, para nós, a teoria moral (a parte sobre a "moralidade"), mas também e sobretudo, no que concerne ao nosso problema, as questões que abrangem a sociologia e a teoria política (tudo isso que é assunto da terceira parte da Filosofia do Direito sob o título de "eticidade"), se deve a que, para ele, as relações concretas que os indivíduos entretêm com os outros e, por consequência, os papéis sociais assumidos por cada indivíduo determinado, não são indiferentes de um ponto de vista ético, em oposição ao que sustentavam os estoicos. Em cada uma dessas relações e em cada um desses papéis, o indivíduo se encontra em demanda de reconhecimento, um reconhecimento que não é mais o de sua qualidade de pessoa, que ele partilha com qualquer outro, mas, ao contrário, disso mesmo que ele é - ele, em particular - na sua diferença em relação aos outros e a qualquer outro. É possível fazer uma leitura comunitarista da terceira parte da Filosofia do Direito, retendo antes de tudo a insistência de Hegel sobre o pertencimento obrigatório do indivíduo a diferentes coletivos: família, corporação, Estado. Mas estas duas leituras negligenciam o fato de que, em todos esses coletivos, a individualidade de cada um, longe de se apagar, se afirma e se precisa adquirindo novas qualidades válidas para um reconheci- 
mento social. O indivíduo é instituído como pessoa pelo reconhecimento jurídico de sua universalidade abstrata, ele se torna alguém pelo reconhecimento social de suas diferenças. Em oposição tanto ao comunitaristas quanto aos liberais de nossa época, Hegel pensa que esses dois tipos de reconhecimento não são excludentes um do outro. Ele considera desejável, além disso, que o segundo tipo seja institucionalizado. Até que ponto pode sê-lo? Trata-se de uma questão difícil a qual Hegel dá uma resposta mais nuançada do que se admite geralmente.

Intersubjetividade e reciprocidade.

Para medir a importância e a significação dessa outra dimensão do reconhecimento, um novo retorno à passagem da Fenomenologia que comentamos mais acima é útil. É comumente admitido que aquilo que está em jogo na luta das consciências seria o reconhecimento mútuo, de sorte que teríamos nesse texto o fundamento de uma teoria da intersubjetividade. Essa leitura me parece, contudo, em parte discutível. É verdade que o fim último da luta é o reconhecimento mútuo e que o reconhecimento procurado por cada um não pode chegar a ter êxito a não ser na condição de ser reconhecimento por parte de uma outra consciência de si. É de impressionar, contudo, lendo detalhadamente essas passagens, que a reciprocidade do reconhecimento esteja ausente de um extremo ao outro da luta, pelo menos se permanecemos no nível de compreensão que é aquele das duas consciências engajadas na luta. Cada uma não combate, com efeito, a não ser em favor de si mesma, e só o observador exterior (o filósofo) sabe que o objetivo perseguido não poderia ser alcançado a não ser por um reconhecimento mútuo. Esse reconhecimento mútuo não se realiza, e isso ocorre porque o resultado da luta é uma relação assimétrica: a relação entre o senhor e o escravo, na qual nenhuma das duas encontra vantagem. "Constituiu-se um reconhecimento unilateral e desigual".$^{36} \mathrm{O}$ servo é servo por ter preferido a vida à liberdade; o senhor é livre, contudo o reconhecimento que ele recebe da consciência servil não pode corresponder à sua expectativa. A etapa ulterior, na qual o servo descobre no seu trabalho o meio de uma outra expressão de sua liberdade, não desemboca mais num reconhecimento mútuo que aboliria a assimetria daquela relação. No termo das duas dialéticas, nenhuma

36. HEGEL, G. Phänomenologie, p. 152; (Fenomenologia, §191, p. 148). 
reconciliação se realiza entre os protagonistas, nenhuma reciprocidade se desenha. O que se indica é somente, do lado do servo, a perspectiva de um processo cultural, processo que é aquele da história humana, e que devemos compreender como o único meio suscetível de produzir aquele reconhecimento mútuo ausente até o momento.

No termo desse processo existe um Estado, e um Estado racional, que concede a cada um o estatuto de pessoa e os direitos que a ele estão ligados. Na injunção: "seja uma pessoa e respeite os outros como pessoas", o reconhecimento recíproco está deveras presente. Mas qual é o alcance desse reconhecimento recíproco, tratando-se de relações que se constituem somente na base do direito abstrato, do qual Hegel procura sublinhar, antes de tudo, o caráter negativo? O direito abstrato não abre senão possibilidades; ele se traduz unicamente por interdições. ${ }^{37}$ Concretamente, ele assegura em primeiro lugar a cada um a propriedade de seus bens, cumpre dizer, uma forma de liberdade que é aquela da "vontade abstrata em geral, ou por isso mesmo aquela de uma pessoa individual, que se relaciona somente consigo mesma". ${ }^{38} \mathrm{E}$ somente com o contrato, o segundo momento do desenvolvimento do direito abstrato, que se esboça algo como uma vontade comum, mais precisamente: comum, não universal. ${ }^{39}$ Os dois parceiros na troca contratual devem certamente se colocar em acordo, cada um deve tomar em consideração os desejos e as vontades do outro, mas isso não impede que, ainda aqui, cada um esteja interessado apenas em si mesmo. É por essa razão, como sabemos, que Hegel se choca por alguns (entre os quais, Kant) reduzirem o casamento a um contrato, e pela mesma razão ele recusa os teóricos contratualistas do Estado. ${ }^{40}$ Em suma, se podemos falar de intersubjetividade e reciprocidade a propósito das relações que os indivíduos entretêm enquanto pessoas, trata-se de uma intersubjetividade bem pobre, e de uma reciprocidade aceita por razões egoístas. A comunidade que se delineia numa relação contratual é uma comunidade de interesses, que se desdobra no mundo do trabalho e das trocas. Não é com este tipo de comunidade, todavia, que Hegel se satisfaz. Para ele, ela não é outra coisa que interpendência.

37. Cf. HEGEL, G. Grundlinien der Pbilosopbie des Recbts, §38, p. 97.

38. Idem, §40, p. 98.

39. Idem, §75, p. 157.

40. Idem, §75 Zusatz, p. 159. 
Portanto, não é certamente por acaso que Hegel não menciona a luta das consciências por reconhecimento senão na parte da Filosofia do Direito consagrada ao direito abstrato. As motivações de uma consciência que busca junto à outra seu reconhecimento como consciência de si são, nós o dizemos, puramente egoístas, e as mesmas do indivíduo reduzido a seu estatuto de pessoa, isto é, de proprietário. Ora, isso torna duvidoso que pudéssemos fazer da luta das consciências a matriz a partir da qual se deixaria desenvolver uma teoria geral do reconhecimento cobrindo todas as formas de relações sociais. Por mais necessário que seja o reconhecimento generalizado da personalidade para assegurar as condições mínimas de uma sociedade livre, continua a existir uma diferença de natureza entre as relações que os indivíduos entretêm enquanto pessoas e aquelas que eles tecem nas esferas concretas da eticidade. As segundas têm uma característica positiva que falta às primeiras. Ora, elas não podem ter essa característica positiva a não ser porque os indivíduos aí se encontram enquanto sujeitos. Esse ser sujeito é aquilo de que Hegel trata na segunda parte da Filosofia do Direito, a moralidade (Moralität), que os leitores estritamente políticos desse texto sempre tiveram tendência a negligenciar, a não ser para reter a crítica virulenta de Hegel ao subjetivismo romântico. Essa crítica, desenvolvida em detalhes no famoso parágrafo 140, é, sem dúvida, essencial para compreender o institucionalismo hegeliano. Mas ela não se reduz à afirmação do "direito da objetividade" contra as pretensões do sujeito de determinar no seu âmago e na sua consciência o que é o bem. Se Hegel experimentou a necessidade de criticar tão severamente os românticos, é porque, admitindo a característica insuficiente das relações puramente jurídicas e reconhecendo "o direito da particularidade do sujeito de encontrar satisfação", ${ }^{41}$ ele a concedeu algo. Deve-se estabelecer contra eles, então, que é possível pensar um "direito da liberdade subjetiva", que não aquele da singularidade individual, naquilo que esta tem (ou pensa ter) de perfeitamente único. Se houve um giro institucionalista no percurso de Hegel (Axel Honneth o assinala na Realpbilosopbie de 1805-1806) deve-se ao fato de que Hegel rapidamente se persuadiu de que a pretensão individual a uma originalidade radical não pode ser socialmente validada, pois esta pretensão vai de encontro à ideia mesma de obrigação, porque ela é a negação de uma sociabilidade organizada.

41. Idem, §124, p. 233. 
Num Estado bem constituído, um indivíduo não é reconhecido apenas como pessoa, mas como um sujeito particular. Essa particularidade não pode, contudo, ter a característica de uma singularidade incomparável. Ela é socializada, ou ainda, institucionalizada sob a forma de uma "retidão" específica segundo os domínios da sociabilidade: $:^{42}$ família, vida profissional, vida política. O indivíduo aceita ocupar um lugar específico e se circunscrever no ordenamento global da sociedade; em troca, ele é "reconbecido (...) em sua própria representação e na representação de outrem" ${ }^{\prime 4}{ }^{43}$ Um adendo ao parágrafo 207 sublinha o fato em questão, nesse reconhecimento, da identidade específica do indivíduo (àquela a qual se recusa o "homem sem qualidades" de Musil): "Quando dizemos que o homem tem de ser algo, entendemos que ele deve pertencer a um estamento determinado; pois esse 'algo' quer dizer que ele é, então, algo substancial. Um homem sem estamento é uma mera pessoa privada e não se encontra em uma universalidade real" ${ }^{44}$ E Hegel anotará ainda, a propósito da corporação, que esta não apenas garante à família a estabilidade de seus rendimentos e de sua riqueza, mas que também "um e outro são, igualmente, reconbecidos, de sorte que o membro de uma corporação não tem a necessidade de nenhuma atestação externa suplementar para provar suas capacidades, dos seus recursos e de sua prosperidade ordinária para provar que ele é algo" ${ }^{45}$ Em resumo, a institucionalização em geral economiza o esforço que o indivíduo deve realizar para ser reconhecido como pessoa (capacidade a qual é concedida a cada um em um Estado racional) e também como indivíduo particular. A família e a corporação são os dois pilares da sociedade civil porque são as esferas de relação entre os seres humanos (aquela da reprodução das gerações e, esta, do trabalho) que podem e devem ser objeto de uma regulação institucional. Aquilo que faz de um indivíduo "alguém" socialmente reconhecido como tal são os direitos e deveres juridicamente codificados que a ele estão vinculados, enquanto membro da famí-

42. Cf. Idem, $§ 207$, p. 359. Hegel anota aí que o indivíduo não se confere realidade senão aceitando restringir-se a uma esfera de ação particular (uma profissão, diríamos hoje). A essa particularização consentida corresponde uma disposição ética específica, que é a "retidão ligada ao estamento".

43. Idem, §207, p. 359.

44. Idem, §207 Zusatz, p. 360.

45. Idem, §253, p. 395. 
lia ou enquanto ele exerce essa ou aquela atividade. O direito em sua totalidade, não somente em sua parte contratual, assegura ao indivíduo um reconhecimento social que ele não precisa procurar e para o qual não precisa a todo momento se provar.

Todavia, e trata-se de um ponto que decorre da crítica de Hegel ao romantismo, tudo isso que constitui a singularidade da pessoa não pode ser institucionalizado. Por mais ampla que seja a compreensão do "direito" em Hegel, ele não abrange a totalidade de tudo aquilo que o indivíduo reivindica como próprio de si, mas somente aquilo que constitui sua identidade social, ou seja, a identidade que nele é reconhecida por todos. Hegel não exclui a existência de uma dimensão privada, no sentido de íntima, mas esta esfera escapa, por sua essência, à institucionalização e não pertence, por consequência, à Filosofia do Direito. A instituição pode mais do que supõe os espíritos eternamente críticos: ela pode garantir os direitos que vão além do direito abstrato, e esta garantia é a grande vantagem que subtrai as relações sociais da contingência do sentimento e das paixões. Mas a instituição não pode responder a uma demanda de reconhecimento disso que é, por definição, ininstitucionalizável. Pouca importa, desse ponto de vista, que interpretemos as corporações de Hegel como um resquício do "Antigo Regime" ou como antecipação dos corpos intermediários da sociedade civil moderna, os partidos e os sindicatos. Essas corporações são de estrutura estatutária, porque a interpretação que Hegel faz da racionalidade das instituições modernas é estatutária, no sentido mais geral de que o único reconhecimento social ao qual os indivíduos podem pretender sob o título de sua particularidade é aquele de seus papéis sociais consagrados pela instituição.

É por isso que me parece contestável flexionar a concepção hegeliana de sociabilidade na direção de uma intersubjetividade socialmente estruturada a partir da amizade ou de uma solidariedade que seria um análogo dela. ${ }^{46}$ Não é um acaso se Hegel, que tinha lá o seu Aristóteles, não diz nada sobre a amizade. ${ }^{47}$ Do amor mesmo, na verdade, ele não diz grandes coisas, exceto a forma que este assume no casamento. Ora, ele se preocupa logo em distinguir a paixão e o sentimento imediato desse amor que se realiza no casamento.

46. Cf. HONNETH, A. La lutte pour la reconnaissance. Paris: Les Éditions du Cerf, 2000.

47. Cf. DERRIDA, J. Politiques de l'amitié. Paris: Galilée, 1994. 
Certamente que a unidade da família repousa sobre o amor, e o coletivo que ela constitui por esse meio se distingue dos outros tipos de coletivos que serão expostos na sequência da Filosofia do Direito (\$158). Mas o objetivo do casamento é depurá-lo tanto quanto possível da arbitrariedade do sentimento. Deve se desfazer, nos diz Hegel, da representação segundo a qual o essencial no casamento seria o amor, "pois o amor, que é um sentimento [Empfindung], permite em todos os aspectos a contingência, uma figura que o elemento ético não pode ter. O casamento deve, assim, ser determinado como se segue: é o amor juridicamente ético [die rechtliche sittliche Liebe], por meio do qual todos os aspectos que é da ordem do passageiro, do humor e do simplesmente subjetivo desaparecem" ${ }^{48}$ Hegel sabe certamente que o espírito de seu tempo favorece mais os casamentos tramados sobre a base da inclinação recíproca que os casamentos arranjados pelas famílias. Ele não dissimula, contudo, que a seus olhos o costume antigo segundo o qual a decisão do casamento vinha primeiro e a inclinação o seguia é "o caminho mais conforme ao ético". ${ }^{49} \mathrm{~A}$ preferência concedida ao casamento por inclinação está ligada, com efeito, à valorização do amor passional que dramas românticos modernos ilustram e que constitui, para Hegel, uma perversão do princípio da particularidade subjetiva. É também essa supervalorização que inspira, segundo ele, o desprezo pela cerimônia do casamento (ilustrado por Lucinde, de Friedrich v. Schlegel), cerimônia que atesta a seus olhos, ao contrário, a característica social do casamento e é, nesse aspecto, indispensável. ${ }^{50}$ O direito, por mais amplamente que seja determinada a sua acepção, não se estende aos sentimentos: "Não se pode fazer-se valer um direito ao amor, pois o sentimento natural é uma disposição própria" ${ }^{51} \mathrm{E}$ por isso o direito do casamento não concerne senão "às coisas que são por natureza exteriores, e não são condicionadas pelo sentimento" ${ }^{152}$ : a disposição dos bens em comum e a educação das crianças. A instituição jurídica visa, certamente, preservar a unidade da família, mas assim que essa unidade se dissolve, por causa do divórcio ou da morte dos pais, é que o direito da família se manifesta. Sem dúvida teria

48. HEGEL, G. Grundlinien der Pbilosopbie des Rechts, §161 Zusatz, p. 310.

49. Idem, $\$ 162$, p. 311.

50. Cf. Idem, $\$ 164$, p. $315 \mathrm{ss}$.

51. Idem, $\$ 159$ adendo, p. 308.

52. Idem, ibidem. 
ele tratado da solidariedade, caso esse termo fizesse parte do léxico político-social de sua época, como fazia o amor. Os parágrafos da Filosofia do Direito consagrados à "polícia" estabelecem a necessidade de segurança pública aos necessitados. A sociedade civil funciona como uma "família universal"; é a ela que cabe, através das disposições institucionais apropriadas ("os regulamentos e mandamentos obrigatórios ${ }^{\prime \prime 13}$ ) amparar as necessidades daqueles que as contingências da existência privam dos meios de viver dignamente. Aqui, uma vez mais, Hegel se recusa a remeter à caridade privada a preocupação em corrigir as disfunções das formas espontâneas da sociabilidade. A caridade não é regulada mais que o amor. Mas isso não impede que os indivíduos privados tenham o que fazer nesse assunto: "malgrado todas as disposições de ordem geral, a moralidade tem suficientemente (aqui) o que fazer". ${ }^{54}$

É possível censurar Hegel por ter "superinstitucionalizado a eticidade"? É verdade que o objetivo das instituições político-jurídicas, cumpre dizer, do direito no sentido lato em que o empregamos, é reduzir tanto quanto possível o ônus deixado aos bons sentimentos, nos quais é arriscado apostar quando se trata de ordenar o social. "Deve-se estimar a situação pública tanto mais perfeita quanto menos resta ao indivíduo por si a fazer segundo sua opinião particular, em comparação com aquilo que é organizado de maneira universal" ${ }^{55}$ Mas a Filosofia do Direito pode ser lida, dessa maneira, como uma exploração que vai às fronteiras do institucionalizável, cumpre dizer, do que, na variedade das relações que os seres humanos são capazes de tecer entre si, comporta uma regulação racionalmente justificada pelos poderes investidos de autoridade. Que o direito positivo, ou seja, a lei, não possa determinar tudo nessas relações, Hegel o diz explicitamente, citando ainda uma vez mais o exemplo da família: "essas relações que repousam sobre o ânimo, o amor e a confiança", a lei não pode penetrar a não ser na medida em que "elas contêm o lado do direito abstrato"; e complementa que "o lado moral e os mandamentos morais, enquanto eles concernem à vontade segundo a sua mais própria

53. Idem, §242, p. 388 .

54. Idem, ibidem.

55. Idem, ibidem. 
subjetividade e particularidade, não podem ser objeto de legislação positiva". ${ }^{56}$

\section{Conclusão}

Durante muito, muito tempo, as interpretações da Filosofia do Direito estiveram concentradas sobre a questão de saber qual parte ela consentia às liberdades das democracias modernas, liberdades sacrificadas em última instância ao poder do Estado, segundo alguns comentadores menos generosos, ou circunscritas para serem mais bem defendidas, segundos outros. Um dos grandes méritos do paradigma do reconhecimento foi o de nos fazer redescobrir, nesse texto, uma contribuição à teoria da intersubjetividade. Esta tem a imensa vantagem, em relação àquelas que se propõem a esse respeito filosofias de inspiração kantiana ou husserliana, de colocar em cena indivíduos concretos cujas relações com o "outro" são sempre relações com outros indivíduos concretos, com os quais, segundo o caso, eles realizam trocas, colaboram, disputam seus direitos respectivos, se casam, dos quais se divorciam, etc. Uma teoria do direito e dos deveres não pode ignorar a diversidade dos papéis que os indivíduos assumem quando mantêm relações uns com os outros. $\mathrm{O}$ reconhecimento que esses indivíduos podem esperar nessas relações concretas concerne aos papéis, e em cada laço particular, a um ou alguns desses papéis somente. Posso ser uma boa professora e uma má esposa, uma boa esposa e uma má mãe, boa professora e uma cidadã relapsa com meus deveres, etc. A multiplicidade desses papéis constitui a sociabilidade. Uma teoria da intersubjetividade permanece abstrata e de pouca utilidade se ela não inclui essa diversidade de relações reais entre os indivíduos. Se ela o faz, ela se esbarra inevitavelmente com a questão da institucionalização. Essas relações concretas, das quais dependem os diferentes tipos de reconhecimento que os indivíduos podem esperar (enquanto pessoas, mas também enquanto indivíduos distintos), podem ser inteiramente determinadas pela ação que aqueles desdobram em cada encontro? Hegel não é o único a duvidar que uma sociabilidade ordenada, suscetível de responder às demandas dos indivíduos, possa se fundar tão-somente na espontaneidade dos sentimentos. Aos defensores da subjetividade romântica, Hegel responde que a instituição libera tanto quanto coage. Ela libera da imediatez e da volatilidade do

56. Idem, $\$ 213$, p. 365. 
desejo, mas também da necessidade de provar em cada encontro o que se é. Ela oferece às relações sociais uma estabilidade de que elas não gozariam se tivessem sempre que se constituir ab ovo. Ela economiza, em diferentes níveis, a luta e o trabalho que se requer na constituição de uma relação. Essa economia não torna, contudo, a luta e o trabalho supérfluos; nós o vimos se tratando do reconhecimento da qualidade de pessoa, concedida a todos formalmente pelo direito racional, mas que não prejulga que todo indivíduo é digno desse reconhecimento. Podemos considerar que o mesmo é verdadeiro para os estatutos sociais, que têm também uma dimensão social. Os títulos e as distinções podem caber aos indivíduos cujos méritos efetivos não justificam essas marcas de reconhecimento social. Ainda que Hegel se pareça mais inquieto com respeito ao formalismo jurídico do que com respeito ao formalismo do reconhecimento, nada permite confundir sua defesa das instituições com uma apologia da aparência. Ele nos convida, acima de tudo, a pensar, em condições certamente bem diferentes daquelas de sua época, um conserto possível da institucionalização do relacionamento social em seus diferentes aspectos e seus limites desejados.

Tradução de Bruno Rosa

\section{Referências}

BALIBAR, E. Identité et différence: Essay concerning Human Understanding II, xxcii, Of Identity and Diversity: L'invention de la conscience. Apresentação, tradução e comentários por E. Balibar. Paris: Les Éditions du Seuil, 1998. DERRIDA. J. Politiques de l'amitié. Paris: Galilée, 1994.

HEGEL, G. Enzyklopädie der philosophischen Wissenschaften im Grundisse. Dritter Teil. In: __. Werke in zwanzig Bänden, Eds. E. Moldenhauer e K. M. Michel, Frankfurt: Suhrkamp, 1986. Werke 10.

Grundlinien der Philosophie des Rechts. In: Werke in zwanzig Bänden, Eds. E. Moldenhauer e K. M. Michel, Frankfurt: Suhrkamp, 1986, Werke 7.

Phänomenologie des Geistes. In: Werke in zwanzig Bänden, Eds. E. Moldenhauer e K. M. Michel. Frankfurt: Suhrkamp, 1986, Werke 3.

Vorlesungen über Rechtsphilosopbie 1818-1831, Band 2. Ed. Karl-Heinz Ilting. Frommann-Holboog, Stutttgart Bad-Constatt, 1974. 
HONNETH, A. La lute pour la reconnaissance. Paris: Les Éditions du Cerf, 2000.

Les pathologies de la liberté. Paris: La Découverte, 2008.

HYPPOLITE, J. Genèse et structure de la Phénoménologie de l'Esprit de Hegel. Paris: Aubier, 1946.

KANT, I. Zum ewigen Frieden. Berlin: Akademie Verlag, 1995.

KÉRVEGAN, J-F. L'effectif et le rationnel. Paris: Vrin, 2007.

KOJÈVE, A. Introduction à la lecture de Hegel. Paris: Gallimard, 1968. 